\title{
Reduced Turn-On Voltage for npn Graded-Base AlGaN/GaN Heterojunction Bipolar Transistors by Thermal Treatment
}

\author{
Shih-Wei Tan and Shih-Wen Lai \\ Department of Electrical Engineering, National Taiwan Ocean University, 2 Peining Road Keelung 202, Taiwan \\ Correspondence should be addressed to Shih-Wei Tan, tanshwei@mail.ntou.edu.tw
}

Received 14 December 2011; Accepted 9 February 2012

Academic Editor: V. P. S. Awana

Copyright ( $) 2012$ S.-W. Tan and S.-W. Lai. This is an open access article distributed under the Creative Commons Attribution License, which permits unrestricted use, distribution, and reproduction in any medium, provided the original work is properly cited.

\begin{abstract}
A thermal treatment was employed to improve the DC performances of npn graded-base AlGaN/GaN heterojunction bipolar transistors (HBTs). Such HBTs without the thermal treatment exhibit a higher turn-on voltage of $6.45 \mathrm{~V}$, a lower current gain of 0.84 , and a lower collector current of $3.18 \times 10^{-4} \mathrm{~mA}$ at $V_{\mathrm{BE}}$ of $4.5 \mathrm{~V}$. The HBTs are examined by thermal treatment with rapid thermal process (RTP) annealing at various times and various temperatures. Experimental results reveal that the HBTs with the thermal treatment exhibit a lowest turn-on voltage of $3.90 \mathrm{~V}$, a highest current gain of 9.55, and highest collector current of $112.2 \mathrm{~mA}$ at $V_{\mathrm{BE}}$ of $4.5 \mathrm{~V}$. The thermal treatment brings forth the most remarkable improvements for the HBTs when the base parasitical Schottky diodes are modified.
\end{abstract}

\section{Introduction}

The npn heterojunction bipolar transistors (HBTs) have received more and more popularity in both wireless and wired consumer products due to the inherent superiority of bipolar devices compared to field-effect devices for linearity, efficiency, and output power, as well as the need for only a single positive power supply $[1,2]$. Recently, the trend in portable electronics has been to achieve greater efficiency at lower bias conditions for longer battery life. Therefore, it has become one of the most important issues to reduce the HBTs base-emitter (B-E) turn-on voltage, $V_{\mathrm{BE}, \mathrm{ON}}$. Typically, two main approaches in reducing $V_{\mathrm{BE}, \mathrm{ON}}$ are (1) adoption of a narrower band-gap material for the base and (2) elimination of the effect of the conduction-band discontinuity $\left(\Delta E_{\mathrm{C}}\right)$ at the B-E junction [3-10].

On the other hand, the GaN-based electronic devices are suitable candidate for high-temperature and high-power application due to their wide bandgap, higher critical electric field strength, and higher electron saturation drift velocity compared to other semiconductor materials. III-nitride technology has been advancing rapidly for several years $[1,2]$. Concerning the adoption of a narrower band-gap material for III-nitride technology, GaN/InGaN HBTs [3-5] are first considered as candidates for the replacement to $\mathrm{AlGaN} / \mathrm{GaN}$ ones [6-10]. However, a large spike at the B-E junction also severely limits the reduction of $V_{\mathrm{BE}, \mathrm{ON}}$. On the other hand, most $\mathrm{p}-\mathrm{InGaN}$-based HBTs are double-heterojunction ones. The blocking effect at base-collector (B-C) heterojunction results in a high knee voltage. Furthermore, the expected reduction of $V_{\mathrm{BE}, \mathrm{ON}}$ is usually insignificant due to increased $\Delta E_{\mathrm{C}}$. In brief, without proper design in abrupt B-E junction for widely studied $\mathrm{HBTs}$, the reduction of $V_{\mathrm{BE}, \mathrm{ON}}$ is still limited.

In this work, we demonstrated grading growth of $\mathrm{AlGaN} / \mathrm{GaN}$ at B-E junction of HBTs to eliminate the effect of $\Delta E_{C}$. Typical measurements of HBTs are the Gummel plot (the collector and base currents, $I_{\mathrm{C}}$ and $I_{\mathrm{B}}$, as a function of base-emitter voltage). The ideality factor of collector current $\left(\eta_{\mathrm{C}}\right)$ is near 1 because collector current is the domination of diffusion current. The base current $\left(I_{\mathrm{B}}\right)$ consider's the diffusion current and generation-recombination current, and the ideality factor of base current $\left(\eta_{\mathrm{B}}\right)$ takes on the values in the range of 1.0 to $2.0[11,12]$. However, in previous reports, measurement results also give higher $V_{\mathrm{BE}, \mathrm{ON}}$ in Gummel plot, moreover; $\eta_{\mathrm{C}}$ and $\eta_{\mathrm{B}}$ are greater than 4 [5-10]. 

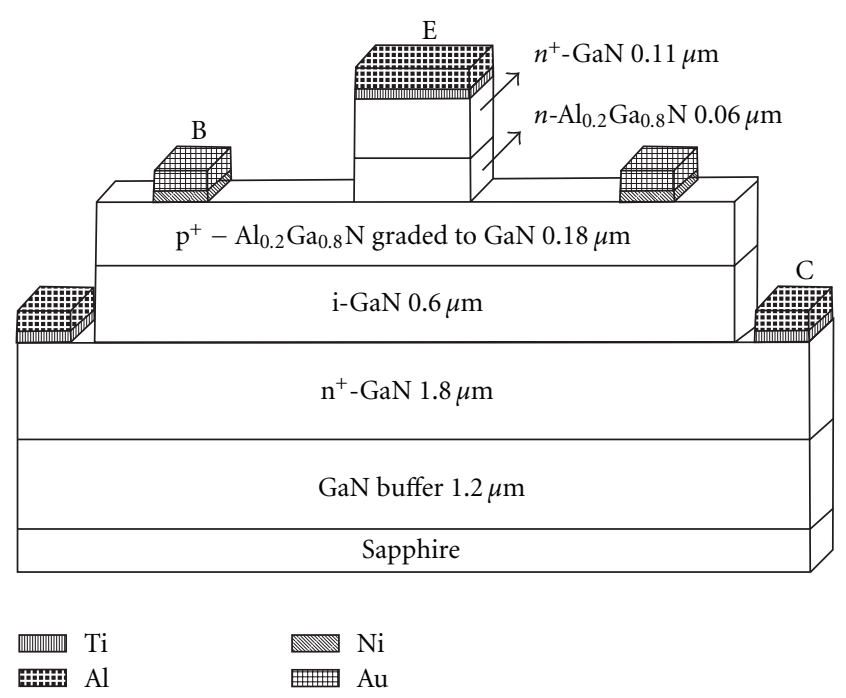

FIgURE 1: Schematic diagram of the studied npn graded-base AlGaN/GaN HBT's.

Unfortunately, that will lead to more power consumption. Therefore, we reported the npn graded-base AlGaN/GaN HBT employing thermal treatment to reduce the $V_{\mathrm{BE}, \mathrm{ON}}$ and ideality factor down to normal. We utilized the thicker base layer of $0.18 \mu \mathrm{m}$ to avoid base $\mathrm{Ni} / \mathrm{Au}$ electrode to penetrate into the collector layer during the thermal treatment.

\section{Device Structure and Fabrication}

The epitaxial layers were grown on c-plane (0001) sapphire substrate by metal-organic chemical vapor deposition (MOCVD). Growth was performed in $\mathrm{H}_{2}$ ambient using trimethylgallium (TMGa) and trimethylaluminum (TMAl) as alkyl sources, and ammonia $\left(\mathrm{NH}_{3}\right)$ as the hydride source. Silane $\left(\mathrm{SiH}_{4}\right)$ and bis(cyclopentadienyl)-magnesium $\left(\mathrm{Cp}_{2} \mathrm{Mg}\right)$ were employed as n-type and p-type dopants, respectively. Shown in Figure 1, a $1.2 \mu \mathrm{m}$ GaN buffer was followed by a $1.8 \mu \mathrm{m} \mathrm{n} \mathrm{n}^{+}-\mathrm{GaN}$ subcollector doped at $5 \times$ $10^{18} \mathrm{~cm}^{-3}$, a $0.6 \mu \mathrm{m} \mathrm{n} \mathrm{n}^{-}-\mathrm{GaN}$ doped at $1 \times 10^{16} \mathrm{~cm}^{-3}$, a $0.18 \mu \mathrm{m}$ graded from $\mathrm{p}^{+}-\mathrm{Al}_{0.2} \mathrm{Ga}_{0.8} \mathrm{~N}$ at the emitter-base junction to $\mathrm{GaN}$ at the base-collector junction and doped at $2 \times 10^{18} \mathrm{~cm}^{-3}$, a $0.06 \mu \mathrm{m} \mathrm{n}-\mathrm{Al}_{0.2} \mathrm{Ga}_{0.8} \mathrm{~N}$ emitter doped at 5 $\times 10^{17} \mathrm{~cm}^{-3}$, and finally a $0.11 \mu \mathrm{m} \mathrm{n}^{+}-\mathrm{GaN}$ cap doped at 5 $\times 10^{18} \mathrm{~cm}^{-3}$. For the device fabrication, the etching process was carried out by high-density plasma (HDP) system with RF power $200 \mathrm{~W}$ in RIE mode, in which photoresist was used as the etching mask instead of $\mathrm{Ni}$ metal. The chamber pressure was kept at 100 Torr and the employed gas sources are $\mathrm{Ar}(20 \mathrm{sccm}), \mathrm{CH}_{4}(25 \mathrm{sccm}), \mathrm{Cl}_{2}(50 \mathrm{sccm})$, and $\mathrm{He}(15 \mathrm{sccm})$. With those parameters, the etching rate is $150 \mathrm{~nm} / \mathrm{min}$. A double-mesa process, emitter mesa and base mesa formations, was employed to fabricate HBT's. One patterned photoresist was used as the mask to remove both the cap and emitter layers during the emitter mesa. The other larger patterned photoresist was used as the mask to remove both base and collector layers during the base mesa. Subsequently, the mesa-completed chip was deposited with
$\mathrm{Ti} / \mathrm{Al}$ bilayers and annealed in $\mathrm{N}_{2}$ ambient at $800^{\circ} \mathrm{C}$ for $30 \mathrm{~s}$ as the emitter and collector electrodes. For the fabrication of base metallization, $\mathrm{Ni} / \mathrm{Au}$ bilayers were deposited on the graded base to form the base electrode. The base electrode spacing to the emitter mesa edge was $50-\mu \mathrm{m}$. The emitter area was $150 \times 300 \mu \mathrm{m}^{2}$.

\section{HBT Performances and Discussion}

To further investigate the effects of the thermal treatment on the output characteristics, the devices were proceeded with rapid thermal process (RTP) annealing at temperatures of $600^{\circ} \mathrm{C}$ and $700^{\circ} \mathrm{C}$ for annealing times of $30 \mathrm{~s}, 60 \mathrm{~s}$, and $90 \mathrm{~s}$. The TLM measurement was also performed for all RTP-annealing graded-base AlGaN/GaN HBT's (A-HBT) to verify contact resistance during the thermal treatment. The measured results indicate no variation occurring for the emitter and the collector contact resistances at such a low annealing time. Figure 2 shows the common-emitter $I$ $V$ s for both N-HBTs and A-HBTs. The common-emitter $I-V$ s for both A-HBTs and N-HBTs are similar and the collector-emitter offset voltage is about $0.2 \mathrm{~V}$ due to the neglected emitter, and collector contact resistances. The changes in $I-V$ s between A-HBTs and N-HBTs are very small except the collector current with input base current above $15 \mu \mathrm{A}$. The enhanced current gain was obtained by RTPannealing and details discussed in Figure 5. Besides, Gummel plot is the most typical measurement that is employed to characterize the performance of the HBTs [5-10, 13-16]. Figure 3 shows the Gummel plots for A-HBT. The Gummel plots for noneannealing graded-base AlGaN/GaN HBTs (NHBTs) were included for comparison. The N-HBT has its $\eta_{\mathrm{B}}$ of 8.66 at low bias reduce to 5.72 at higher bias. It is similar to previous reports [5-10]. Whereas the entire AHBTs exhibit an immovable $\eta_{\mathrm{B}}$ except that operate at high current injection. As the annealing temperature and the annealing time increases, $\eta_{\mathrm{B}}$ decreases gradually from 6.52 to 1.90 . $\eta_{\mathrm{B}}$ of 1.90 is close to the ideality factor of generationrecombination current equal to 2 when annealing condition is at $700^{\circ} \mathrm{C}$ for $90 \mathrm{~s}$.

$\eta_{\mathrm{C}}$ for N-HBT equal to 4.32 is similar to previous reports [5-10]. $\eta_{\mathrm{C}}$ for A-HBT are 3.68, 4.51, 4.51, 1.09, 1.09, and 1.09 for annealing condition at $600^{\circ} \mathrm{C}$ for $30 \mathrm{~s}, 600^{\circ} \mathrm{C}$ for $60 \mathrm{~s}, 600^{\circ} \mathrm{C}$ for $90 \mathrm{~s}, 700^{\circ} \mathrm{C}$ for $30 \mathrm{~s}, 700^{\circ} \mathrm{C}$ for $60 \mathrm{~s}$, and $700^{\circ} \mathrm{C}$ for $90 \mathrm{~s}$, respectively. Clearly, $\eta_{\mathrm{C}}$ of 1.09 is close to ideality factor of diffusion current equal to 1 when annealing condition is at $700^{\circ} \mathrm{C}$ for $90 \mathrm{~s}$. This phenomenon can also be found that the base parasitical Schottky diodes are modified. Detailed discussions have been demonstrated in next section. The ratios of $\eta_{\mathrm{B}}$ to its corresponding $\eta_{\mathrm{C}}$ are in the range of 1 to 2 for all A-HBT and N-HBT. It is found that base current considers the components of diffusion current and generation-recombination current at forward bias, and $\eta_{\mathrm{B}}$ is in the range of $1 \sim 2$.

On the other hand, the applied $V_{\mathrm{BE}}$ creating the condition of the $I_{\mathrm{C}}$ equals to $100 \mathrm{~A} / \mathrm{cm}^{2}$ and is defined as the turnon voltage $\left(V_{\mathrm{BE}, \mathrm{ON}}\right)$ and shown in Figure $4(\mathrm{a})$. The $V_{\mathrm{BE}, \mathrm{ON}}$ values of N-HBT are $6.45 \mathrm{~V}$ while they are $6.12,5.97,5.5$, 


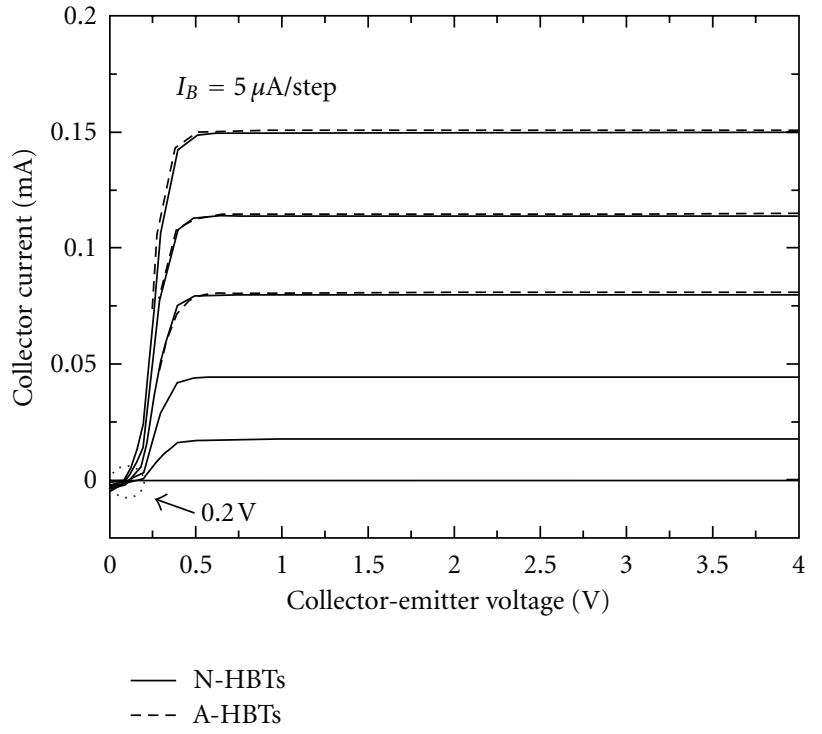

FIGURE 2: Measured collector current as a function of collectoremitter voltage for both $\mathrm{N}$ - and A-HBTs.

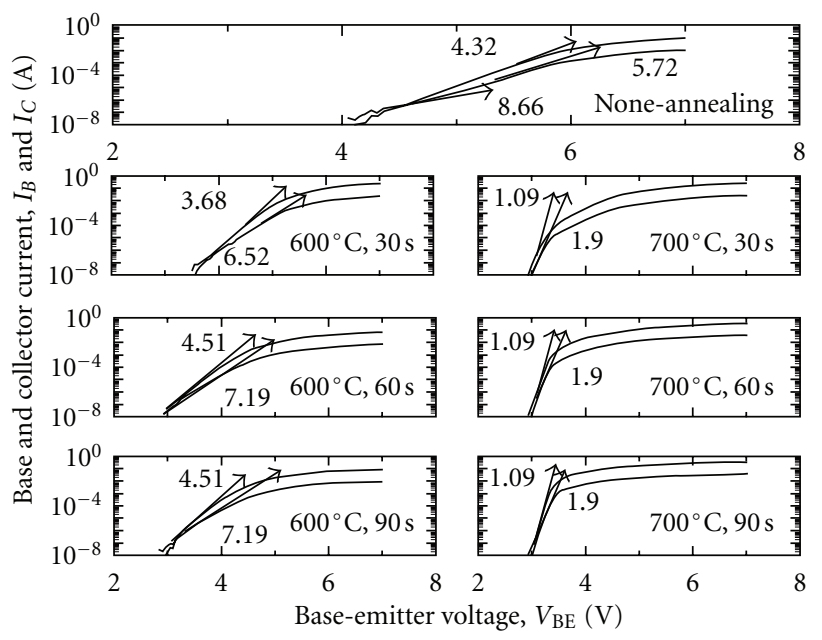

Figure 3: Gummel plots for all fabricated npn graded-base AlGaN/GaN HBT's.

$4.85,4.42$, and $3.90 \mathrm{~V}$ for A-HBT annealed at $600^{\circ} \mathrm{C}$ for $30 \mathrm{~s}$, $600^{\circ} \mathrm{C}$ for $60 \mathrm{~s}, 600^{\circ} \mathrm{C}$ for $90 \mathrm{~s}, 700^{\circ} \mathrm{C}$ for $30 \mathrm{~s}, 700^{\circ} \mathrm{C}$ for $60 \mathrm{~s}$, and $700^{\circ} \mathrm{C}$ for $90 \mathrm{~s}$, respectively. Accordingly, we believe that a higher $V_{\mathrm{BE}, \mathrm{ON}}$ is resulted from a finite reverse-voltage drop occurring for the base parasitical Schottky diode. Figure 4(b) shows the collector current as a function of annealing time. The enhanced collector current was obtained by elevating the annealing temperature to $700^{\circ} \mathrm{C}$. As the annealing time is increasing and applied $V_{\mathrm{BE}}$ is $4.5 \mathrm{~V}$, the collector current increases from $3.18 \times 10^{-4} \mathrm{~mA}$ to $112.2 \mathrm{~mA}$ at $700^{\circ} \mathrm{C}$.

Figure 5 shows the current gain as a function of $V_{\mathrm{BE}}$. We observe that the current gain gradually increases with $V_{\mathrm{BE}}$ and displays a high plateau at $700^{\circ} \mathrm{C}$ for $90 \mathrm{~s}$. The enhanced current gain was obtained by elevating the annealing temperature from $600^{\circ} \mathrm{C}$ to $700^{\circ} \mathrm{C}$. The current gain is enhanced at

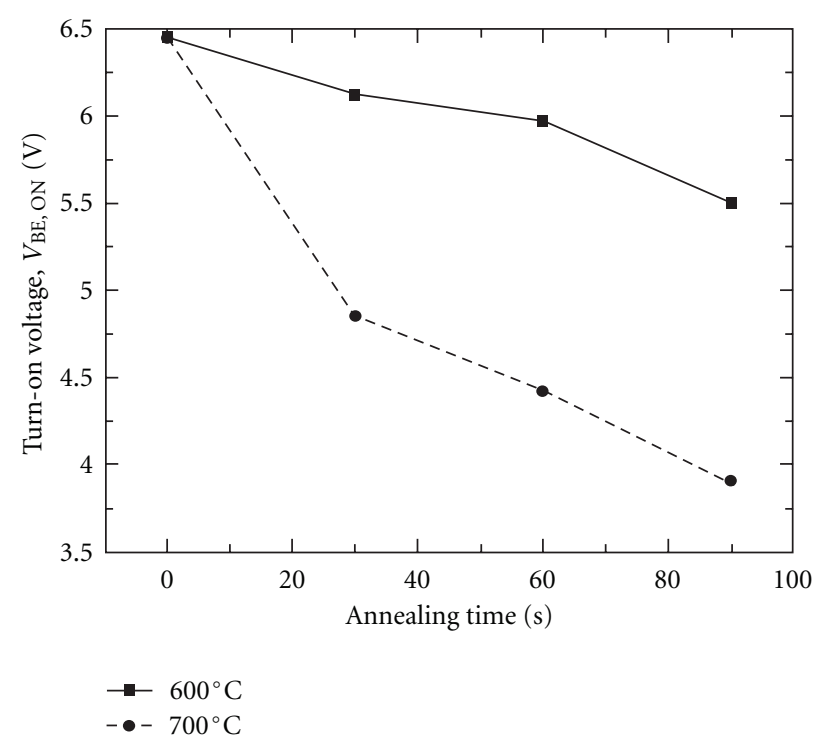

(a)

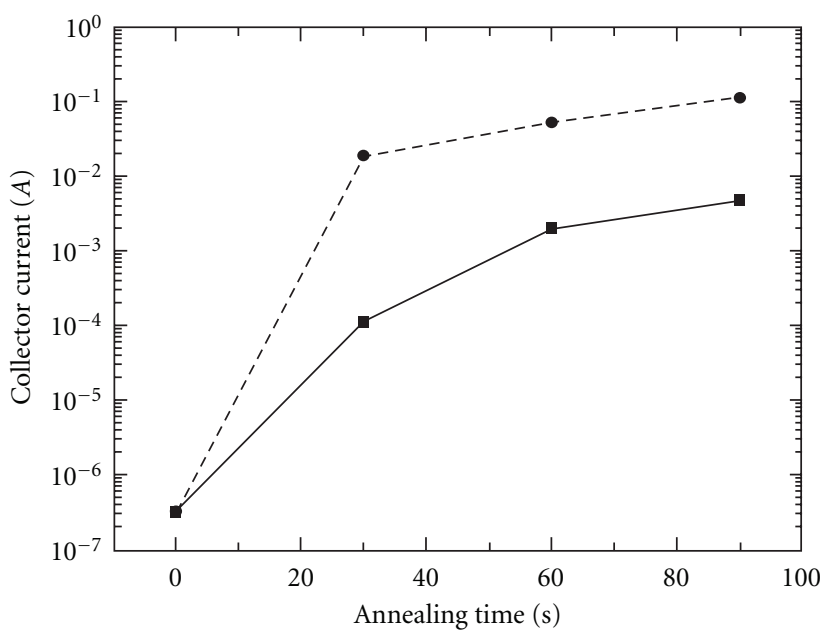

$V_{\mathrm{BE}} @ 4.5 \mathrm{~V}$

$\rightarrow-600^{\circ} \mathrm{C}$

- $700^{\circ} \mathrm{C}$

(b)

FIGURE 4: (a) Turn-on voltage. (b) collector current as a function of annealing time for all fabricated npn graded-base AlGaN/GaN HBT's. A N-HBT's is also included for comparisons.

the same applied $V_{\mathrm{BE}}$ of $4.5 \mathrm{~V}$ after the thermal treatment. As the annealing time is increasing, the current gain increases from 9.10 to 9.55 at $700^{\circ} \mathrm{C}$.

\section{MSM Diodes Measurement}

In order to further verify the behaviors in the studied AHBTs by thermal treatment, when HBTs fabrication, metalsemiconductor-metal (MSM) diodes have been fabricated by evaporated $\mathrm{Ni} / \mathrm{Au}$ bilayers on the graded-base layer. Figure 6 shown the measured current-voltage $(I-V)$ curves for the noneannealing MSM diodes and the RTP-annealing ones 


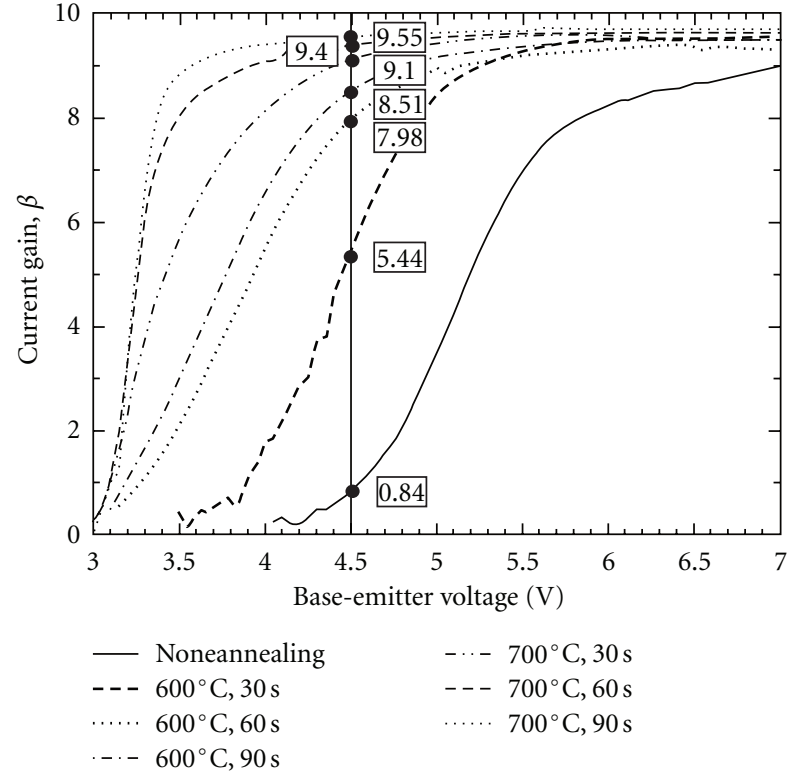

Figure 5: Current gain as a function of base-emitter voltage for all fabricated npn graded-base AlGaN/GaN HBT's. A N-HBT's is also included for comparisons.

with the same chip and the same device dimension. Figures $6(\mathrm{a})$ and $6(\mathrm{~b})$ are measured at $600^{\circ} \mathrm{C}$ and $700^{\circ} \mathrm{C}$, respectively, for $30 \mathrm{~s}, 60 \mathrm{~s}$, and $90 \mathrm{~s}$. $I-V$ curves for noneannealing MSM diodes are also included for comparisons. As increase the annealing temperature and the annealing time, the measured $I-V$ curves for MSM diode are gradually into the Ohmic contacts. Furthermore, the curve at the annealing conditions of $700^{\circ} \mathrm{C}$ for $90 \mathrm{~s}$ exhibits the better characteristics of an Ohmic contacts, and the value is $27 \Omega$. All results and comparisons discussed indicate that the thermal treatment can really eliminates the base parasitical Schottky diodes. Accordingly, the base metallization in previous reports [510] certainly has the base parasitical Schottky diode.

\section{Conclusion}

In conclusions, we report on the characterization and comparison between AlGaN/GaN graded-base N-HBTs and AHBTs and then demonstrate what improvements annealing can yield in this work. Such N-HBTs exhibits a higher turnon voltage of 4.55 , a lower current gain of 0.84 , and lower collector current of $3.18 \times 10^{-4} \mathrm{~mA}$ at $V_{\mathrm{BE}}$ of $4.5 \mathrm{~V}$. To study the effects of thermal treatment on device performances, experimental results also reveal that the A-HBTs exhibit a lowest turn-on voltage of 3.09, a highest current gain of 9.55, and highest collector current of $112.2 \mathrm{~mA}$ at $V_{\mathrm{BE}}$ of $4.5 \mathrm{~V}$. For the device fabrication, HBTs and MSM diodes performed on graded base layer were simultaneously fabricated on the same chip. Actually, the characteristics of MSM diodes can well describe those of HBTs at the base. Therefore, the base metallization certainly has the base parasitical Schottky diode. The base parasitical Schottky diodes cause the higher $V_{\mathrm{BE}, \mathrm{ON}}$ and the greater ideality factor. The thermal treatment

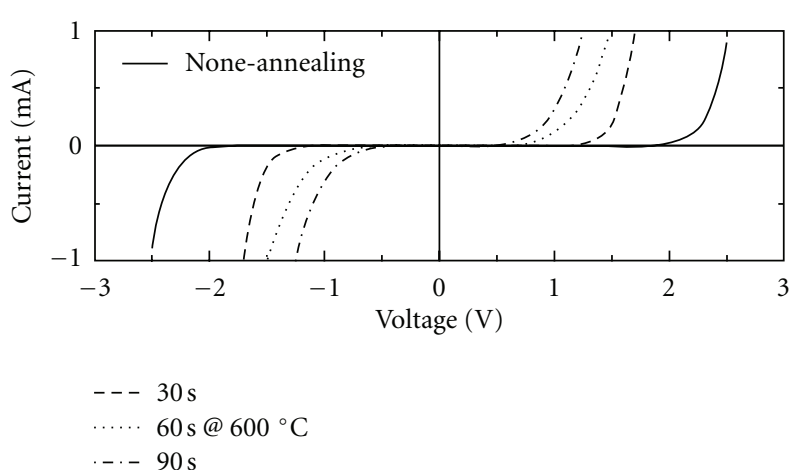

(a)

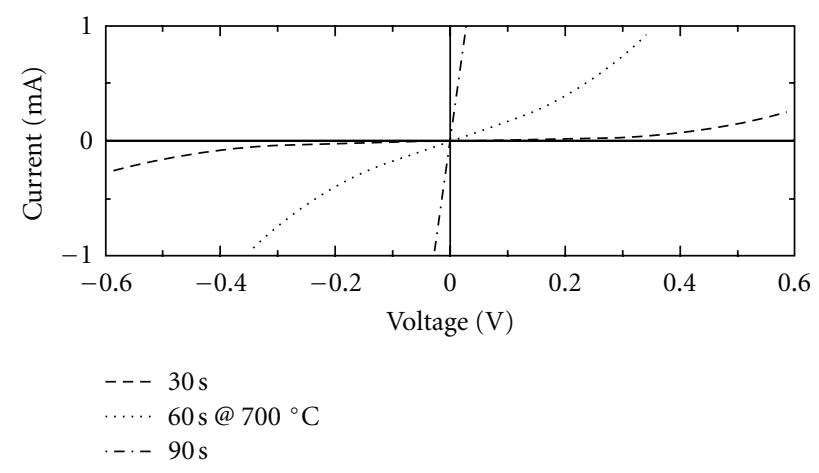

(b)

FIGURE 6: Measured currents of MSM diode as a function of applied voltage for noneannealing and RTP-annealing.

brings forth the most remarkable improvements for the HBTs when the base parasitical Schottky diodes are modified.

\section{Acknowledgment}

This work is partly supported by National Science Council under the contract no. NSC 99-2221-E-019-043.

\section{References}

[1] M. S. Shur and M. A. Khan, "GaN/AlGaN heterojunction device: photodetector and field-effect transistors," MRS Bulletin, vol. 27, no. 2, pp. 44-50, 1997.

[2] Y. F. Wu, B. P. Keller, P. Fini et al., "High Al-content AlGaN/GaN MODFET's for ultrahigh performance," IEEE Electron Device Letters, vol. 19, no. 2, pp. 50-53, 1998.

[3] A. Nishikawa, K. Kumakura, and T. Makimoto, "Temperature dependence of current-voltage characteristics of npntype GaNInGaN double heterojunction bipolar transistors," Applied Physics Letters, vol. 91, no. 13, Article ID 133514, 2007.

[4] B. F. Chu-Kung, M. Feng, G. Walter et al., "Graded-base InGaN/GaN heterojunction bipolar light-emitting transistors," Applied Physics Letters, vol. 89, no. 8, Article ID 082108, 2006.

[5] S. Yoshida and J. Suzuki, "High-temperature reliability of GaN metal semiconductor field-effect transistor and bipolar junction transistor," Journal of Applied Physics, vol. 85, no. 11, pp. 7931-7934, 1999. 
[6] L. S. McCarthy, P. Kozodoy, M. J. W. Rodwell, S. P. DenBaars, and U. K. Mishra, "AlGaN/GaN heterojunction bipolar transistor," IEEE Electron Device Letters, vol. 20, no. 6, pp. 277-279, 1999.

[7] B. S. Shelton, D. J. H. Lambert, J. J. Huang et al., "Selective area growth and characterization of $\mathrm{AlGaN} / \mathrm{GaN}$ heterojunction bipolar transistors by metalorganic chemical vapor deposition," IEEE Transactions on Electron Devices, vol. 48, no. 3, pp. 490-494, 2001.

[8] H. Xing, P. M. Chavarkar, S. Keller, S. P. DenBaars, and U. K. Mishra, "Very high voltage operation (> $330 \mathrm{~V}$ ) with high current gain of AlGaN/GaN HBTs," IEEE Electron Device Letters, vol. 24, no. 3, pp. 141-143, 2003.

[9] J. B. Limb, H. Xing, B. Moran, L. McCarthy, S. P. DenBaars, and U. K. Mishra, "High voltage operation (> $80 \mathrm{~V}$ ) of GaN bipolar junction transistors with low leakage," Applied Physics Letters, vol. 76, no. 17, pp. 2457-2459, 2000.

[10] C. Monier, F. Ren, J. Han et al., "Simulation of NPN and PNP $\mathrm{AlGaN} / \mathrm{GaN}$ heterojunction bipolar transistors performances: limiting factors and optimum design," IEEE Transactions on Electron Devices, vol. 48, no. 3, pp. 427-432, 2001.

[11] S. W. Tan, "The influence of ambient temperature on the forward-bias electrical characteristics of $\mathrm{p}-\mathrm{n}$ heterojunction and homojunction interface," Journal of the Electrochemical Society, vol. 154, no. 5, pp. H365-H369, 2007.

[12] S. M. Sze, Semiconductor Devices: Physics and Technology, 2nd Edition, John Wiley \& Sons, New York, NY, USA, 2002.

[13] Y. S. Lin, D. H. Huang, Y. W. Chen, J. C. Huang, and W. C. Hsu, "Delta-doped InGaP/GaAs heterostructure-emitter bipolar transistor grown by metalorganic chemical vapor deposition," Thin Solid Films, vol. 515, no. 7-8, pp. 3978-3981, 2007.

[14] T. P. Chen, C. J. Lee, W. S. Lour, D. F. Guo, J. H. Tsai, and W. C. Liu, "On the breakdown behaviors of InP/InGaAs based heterojunction bipolar transistors (HBTs)," Solid-State Electronics, vol. 53, no. 2, pp. 190-194, 2009.

[15] T. P. Chen, C. J. Lee, S. Y. Cheng et al., "Effect of emitter ledge thickness on inGaPGaAs Heterojunction bipolar transistors," Electrochemical and Solid-State Letters, vol. 12, no. 2, pp. H41H43, 2009.

[16] S. W. Tan, H. R. Chen, W. T. Chen, M. K. Hsu, A. H. Lin, and W. S. Lour, "Characterization and modeling of threeterminal heterojunction phototransistors using an InGaP layer for passivation," IEEE Transactions on Electron Devices, vol. 52, no. 2, pp. 204-210, 2005. 

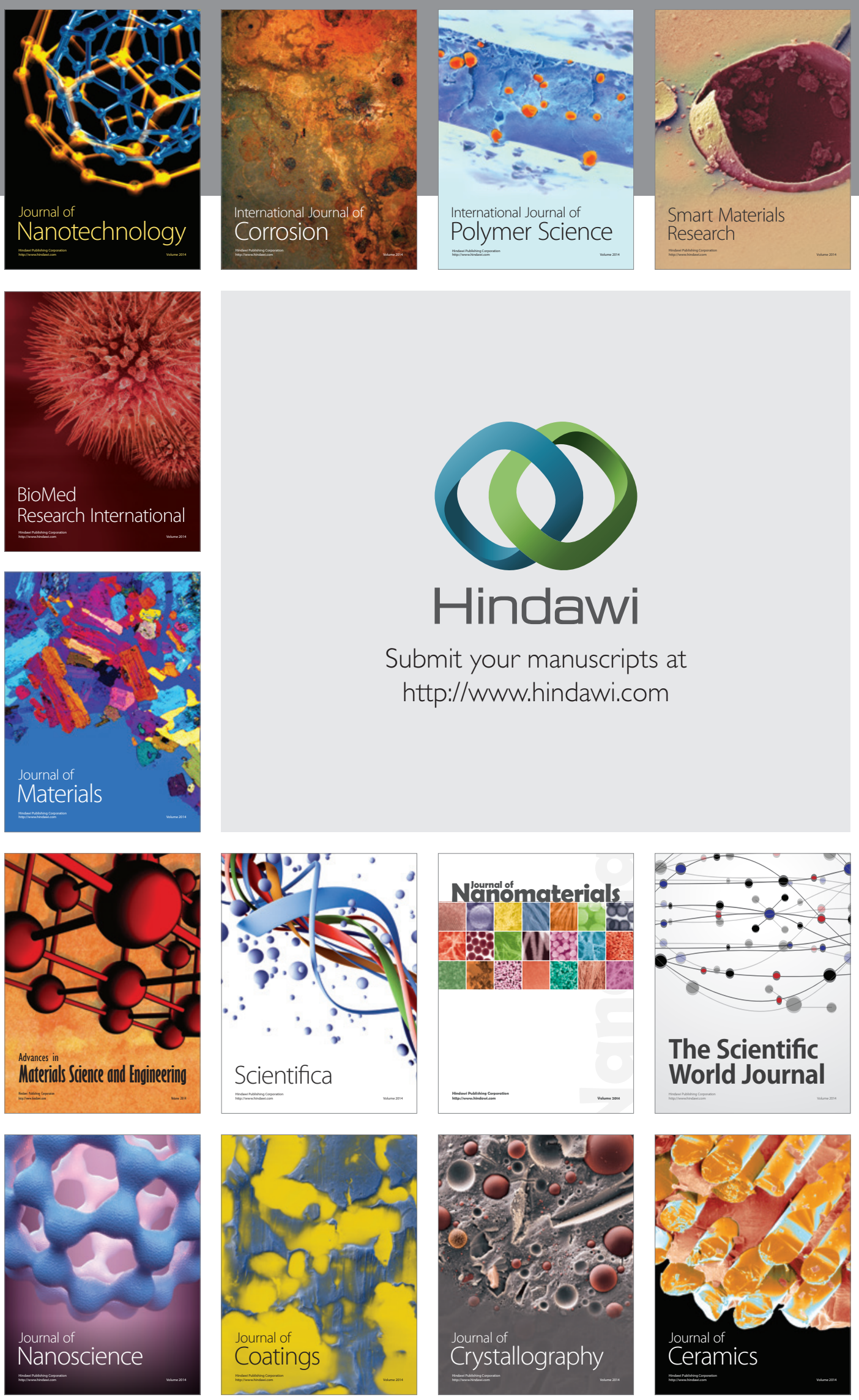

The Scientific World Journal

Submit your manuscripts at

http://www.hindawi.com

\section{World Journal}

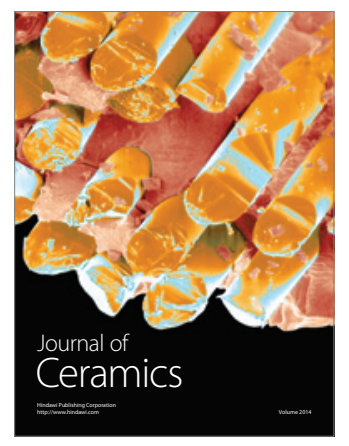

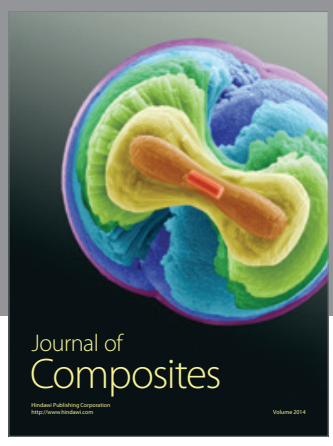
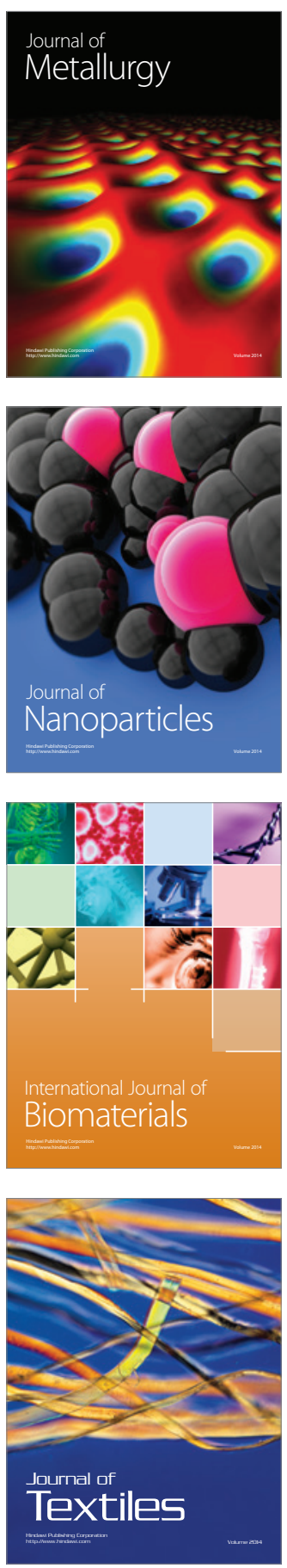